\title{
Nova ocorrência de Peripatus (Macroperipatus) acacioi Marcus \& Marcus (Onycophora, Peripatidae) no estado de Minas Gerais, Brasil
}

\author{
Gilson Alexandre de Castro ${ }^{1}$ \\ Clésio Castro da Silva ${ }^{2}$
}

\begin{abstract}
New record of Peripatus (Macroperipatus) acacioi Marcus \& Marcus (Onycophora, Peripatidae) in Minas Gerais State (Brazil). Peripatus acacioi Marcus \& Marcus, 1955 is a new record to the state Minas Gerais (Brasil). A description and a ilustrations is given.

KEY WORDS. Onycophora, Peripatus acacioi, new record, Brazil
\end{abstract}

As espécies do gênero Peripatus Guilding, 1825 são dos taxa pouco conhecidos dentro dos onicóforos brasileiros. MARCUS \& MARCUS (1955) registraram exemplares de Peripatus acacioi Marcus \& Marcus, 1955 na Estação Ecológica do Tripui ( $20^{\circ} 17^{\prime} 15^{\prime \prime}$ S e 4330'29'W, Ouro Preto, Minas Gerais). A Estação Ecológica do Tripuí com cotas altimétricas variando entre 1.180 a $1.300 \mathrm{~m}$, está assentada sobre rochas metassedimentares pelíticas do período Pré-Cambriano Superior (550 a 350 milhões de anos).

Os espécimes de $P$. acacioi foram encontrados no Parque Estadual do Ibitipoca ( $21^{\circ} 42^{\prime} \mathrm{S}$ e $43^{\circ} 53^{\prime} \mathrm{W}$ ) (Fig. 1), dentro da unidade geomorfológica da Serra da Mantigueira (ANDRADE \& SouZA 1995) pertencente ao domínio das faixas de Dobramento Remobilizados do Brasil, que contém ainda o Planalto de Andrelândia (FIGUEIREDO \& TEIXEIRA 1996) e apresenta cotas altimétricas entre 1.050 à $1.784 \mathrm{~m}$.

O Parque é um fragmento remanescente natural da vegetação do estado de Minas Gerais, sendo importante do ponto de vista liqueinológico.

A geologia do Parque Estadual está representada por um conjunto litológico metassedimentar de idade Proterozóica Inferior, com dois eixos de anticlinal com caimento sudoeste e um eixo de sinclinal com caimento também sudoeste, onde percorre o Rio do Salto (FIGUEIREDO \& TEIXEIRA 1996).

O presente relato amplia a distribuição geográfica de $P$. acacioi para o Brasil (Minas Gerais) e apresenta informações sistemáticas dessa espécie.

No período entre outubro de 1995 à janeiro de 1997, efetuaram-se coletas mensais na mata primária estacional semidecidual montana (CASTRO \& D'AGOSTO 1999), com árvores de 20 a 30 m de altura com predominância de indivíduos da família Lauraceae.

1) Departamento de Zoologia, ICB, Universidade Federal de Juiz de Fora. Campus Universitário, 36036-330 Juiz de Fora, Minas Gerais, Brasil. E-mail: gilalex@zaz.com.br

2) Curso de Ciências Biológicas, ICB, Universidade Federal de Juiz de Fora. 


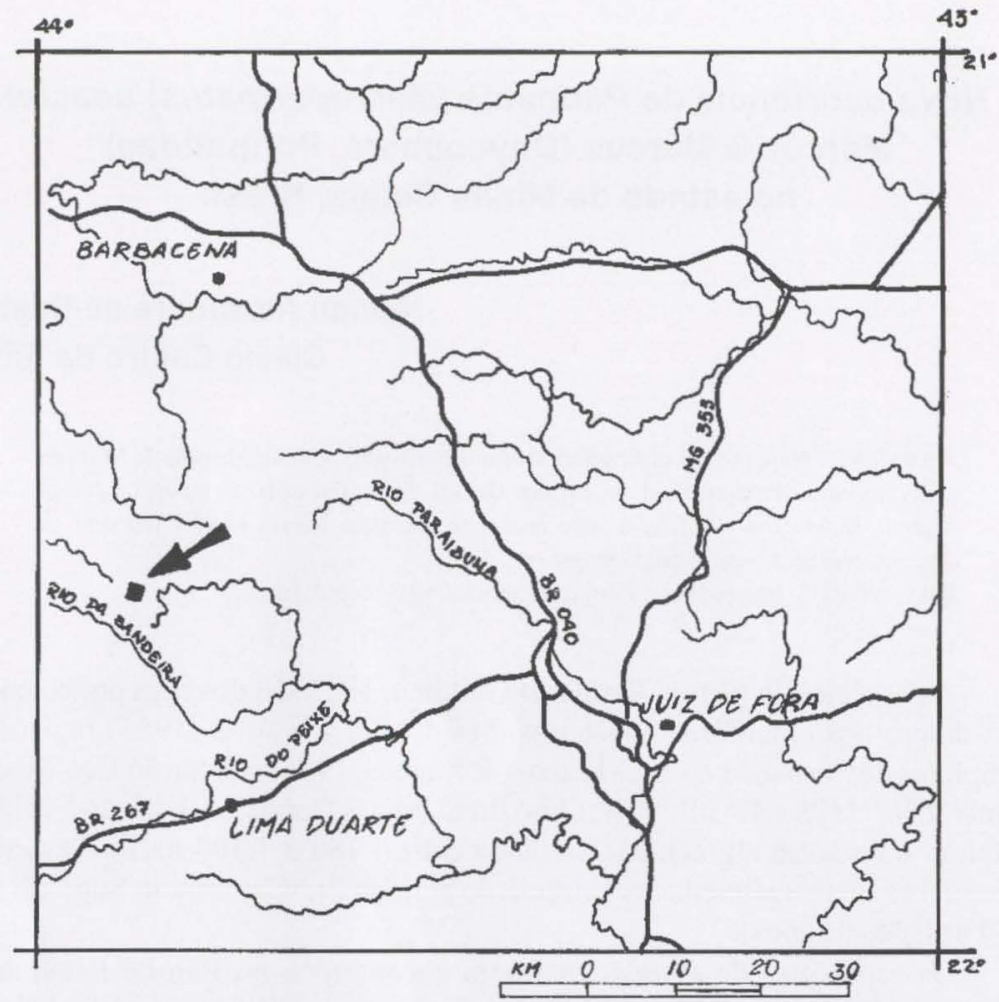

Fig. 1. Localização do Parque Estadual do Ibitipoca, Minas Gerais, Brasil.

As técnicas de procura utilizadas, foram as seguintes: busca manual com pinça em troncos e folhas de árvores e arbustos, entre musgos, sob troncos caídos e revolvimento superficial dos folhelhos no chão da mata.

Foram coletados cinco espécimens de $P$. acacioi, em 09 de novembro de 1996, que foram levados vivos para o laboratório de invertebrados, anestesiados em vapores de éter e acondicionados em vidros de cor âmbar, etiquetados, que continha uma solução de álcool a $70 \%$. Atualmente estão na coleção de Invertebrados do Departamento de Zoologia do Instituto de Ciências Biológicas da Universidade Federal de Juiz de Fora.

Peripatus acacioi habita geralmente cavidades e fendas no solo, em obscuridade total ou penumbra, em temperaturas não muito elevadas (menores que $20^{\circ} \mathrm{C}$ ) (Marcus \& Marcus 1955; Monge-NaJera 1994; Monge-NaJera \& Alfaro 1995).

Os espécimens analisados tinham a superfície corporal aveludada e de cor marron-vinho. O comprimento em média foi de $24 \mathrm{~mm}$ (mínimo: $23 \mathrm{~mm}$, máximo: $25 \mathrm{~mm}$ ) enquanto o diâmetro é de $2,5 \mathrm{~mm}$. O peso corporal em média de $150,80 \mathrm{mg}$ (mínimo: $26 \mathrm{mg}$ e máximo: $310 \mathrm{mg}$ ). Na região cefálica encontram-se duas antenas não muito espessas, aneladas e com papilas espinhosas, com um par de ocelos de 
cerca de $1 \mathrm{~mm}$ de diâmetro. A boca tem um par de mandíbulas cortantes e um dente maior envolvido com um pequeno dente acessório representado por dez ou onze fileiras. Conforme MONGE-NAJERA (1994), os espécimens analisados apresentam o corpo com 26 a 28 pares de parapódios da mesma forma e dimensões, sendo que no último par denotam-se aberturas genitais que são em número de duas. $\mathrm{O}$ ânus situa-se no final do corpo.

Estas características não são diferentes quanto MARCUS \& MARCUS (1955) descreveram pela primeira vez os espécimens de $P$. acacioi, apenas não haviam apresentado o peso e nem as variações de tamanho entre os $P$. acacioi analisados.

\section{REFERÊNCIAS BIBLIOGRÁFICAS}

AndRade, P.M. DE \& H.C. DE SouzA. 1995. Contribuição ao conhecimento da vegetação do Parque Estadual do Ibitipoca, Lima Duarte, MG. Rev. Árvore, Viçosa, 19 (2): 249-261.

CASTRO, G.A DE \& M. D'AGosto. 1999. Ocupação ambiental dos oligoquetos terrestres em diferentes ambientes fitofisionômicos do Parque Estadual do Ibitipoca - Minas Gerais. Rev. Brasil. Zoociências, Juiz de Fora, 1 (1): 103-114.

Figueiredo, M.C.H. \& W. TeIXEIRA. 1996. The Mantiqueira metamorphic complex, eastern Minas Gerais state: preliminary geochronological and geochemical results. An. Acad. Bras. Ci. 68 (2): 223-246.

Marcus, E. \& E. Marcus. 1955. A new Peripatus from Minas Gerais, Brazil. An. Acad. Bras. Ci. 27: 189-193.

MONGE-NAJERA, J. 1994. Ecological biogeography in the phylum Onycophora. Biogeographica, Hague, 70 (3): 111-123.

Monje-NaJera, J. \& J.P. Alfaro. 1995. Geographic variation of habitats in Costa rican velvet worms (Onychophora: Peripatidae). Biogeographica, Hague, 71 (3): 97-108.

Recebido em 31.VIII.2000; aceito em 18.VII.2001. 